\title{
Inovação \& propriedade intelectual: panorama dos agentes motores de desenvolvimento e inovação
}

\author{
Innovation \& intellectual property: behavior of innovation and \\ development drivers
}

\author{
Flávio Pietrobon-Costa \\ Celso Carlino Maria Fornari Junior ${ }^{1}$ \\ Thiago Martins Ramos dos Santos
}

\begin{abstract}
Resumo: O desenvolvimento social e o crescimento econômico são fortemente influenciados por informações e pela geração de conhecimento, fundamentais para a determinação das vantagens competitivas de países, organizações e empresas. Produção mais eficiente e solução aos problemas sociais têm em comum a necessidade de implantação de novas ideias, de geração de conhecimento e de geração de inovação. Desenvolvidos por diferentes atores ou agentes sociais, requerem a integração dos Agentes Motores de Desenvolvimento e de Inovação: produtores econômicos principais, produtores de conhecimento, e agentes de apropriação de inovações. Analisamos indicadores de crescimento econômico, de produção científica e de geração de inovações, do Brasil e da Bahia, correlacionando-os, e traçando um panorama por séries temporais da relação entre os agentes motores de desenvolvimento e inovação e suas influências. Verificamos que os três agentes dependem de forma interativa uns dos outros, mantendo uma interdependência. Para realizar investimento de vulto em pesquisa e propriedade intelectual, é preciso haver produtores econômicos interessados em se fortalecerem e se tornarem um diferencial com relação a concorrentes. Para que a sociedade cresça sobre bases sustentáveis, é preciso simultaneamente investimentos em pesquisa científica, tecnologia e inovações, com impulso de ação afirmativa e continuada dos agentes de inovação.
\end{abstract}

Palavras-chave: Inovação. Transferência e difusão do conhecimento. Desenvolvimento social. Crescimento econômico. Agentes motores de inovação.

\begin{abstract}
Social development and economic growth are strongly influenced by knowledge generation and information exchange, which are key factors for competitive advantage of countries, organizations, and enterprises. New ideas and generation of knowledge and innovation are necessary for a more efficient production and solution to social problems developed by different actors or social agents. They require the integration of Drivers of Development and Innovation: major economic producers, knowledge producers, and innovation property agents. Indicators of economic growth, scientific production, and innovation generation of Brazil and Bahia State were analyzed investigating their relationships and observing, by time series, the behavior of drivers of development and innovation and their influences. It was found that that these three actors (or agents) are interdependent and interactive. For a substantial investment in scientific research and intellectual property, the economic producers must be growth-oriented to achieve strong competitive advantage. For a sustainable development of human society, a simultaneous investment in scientific research, technology, and innovations is needed with continuous active support of innovation agents.
\end{abstract}

Keywords: Innovation. Knowledge transfer and diffusion. Social development. Economic growth. Drivers of innovation.

\section{Introdução}

As habilidades de gestão do conhecimento e de inovações são condicionadas pelo compartilhamento de informações e de geração de conhecimento (PIETROBON-COSTA et al., 2009; BEVILACQUA; GALEÃO; PIETROBON-COSTA, 2011). Atualmente são considerados vetores fundamentais para a determinação das vantagens competitivas de países e empresas (FERREIRA; ROCHA; ELISA, 2001), influindo no crescimento econômico, na geração de riqueza e na melhoria da qualidade de vida, ou seja, no desenvolvimento da sociedade humana.

O planejamento e efetivação do desenvolvimento social e econômico, com caráter de sustentabilidade, demandam respostas novas a novos problemas. Requerem a elaboração de conhecimento. A partir dos anos 1980, a revolução científico-tecnológica modificou fortemente tanto métodos produtivos quanto as relações sociais (BAUMGARTEN, 2001).

\footnotetext{
${ }^{1}$ Departamento de Ciências Exatas e Tecnológicas, Universidade Estadual de Santa Cruz - UESC, Rod. Ilhéus-Itabuna, Km 16, s/n, Salobrinho, CEP 45662-900, Ilheus, BA, Brasil, e-mail: pietrobon.costa@pq.cnpq.br
}

Recebido em 9/7/2010 — Aceito em 26/4/2012

Suporte financeiro: FAPSEB, UESC - Projeto de Implantação do Núcleo de Inovação Tecnológica - NIT. 
Na sociedade do conhecimento, conceitos como a inovação tecnológica e social, sustentabilidade social, seletividade e sustentabilidade ambiental são essenciais para a análise e a compreensão da posição relativa, dinâmica, dos países e organizações (HAN et al., 2012; TOMALA; SÉNÉCHAL, 2004; GREEN; VERGRAST, 2002).

Produção mais eficiente e solução para os problemas sociais têm em comum a necessidade de implantação de novas ideias. A resposta a essas demandas requer inovação, seja ela social ou tecnológica, e aplicação de novas tecnologias, no sentido amplo, de aplicação do conhecimento, e não no sentido restrito, de aperfeiçoamento pela incorporação do novo na construção de equipamentos, serviços ou industrialização de produtos. Inovações tecnológicas serão necessariamente combinadas a inovações sociais pelo menos nos próximos cinquenta anos (GREEN; VERGRAGT, 2002), para oferecer respostas que integrem a satisfação das necessidades de recursos da sociedade humana, com melhora da qualidade de vida e sustentabilidade ambiental e social, atendendo às demandas e soluções dos problemas de desenvolvimento social e crescimento econômico.

Os processos de inovação, de geração de conhecimento e de crescimento econômico são desenvolvidos por diferentes atores ou agentes sociais (LEYDESDORFF, 2012; METCALFE; FONSECA; RAMLOGAN, 2002). A geração e disseminação do conhecimento para desenvolvimento da sociedade requer a integração dos Agentes Motores de Desenvolvimento e de Inovação (AMDI) na forma de: produtores econômicos principais, responsáveis pela industrialização $(\mathrm{PE})$, produtores de conhecimento (PC), e agentes de apropriação de inovações, incluindo serviços em seus diversos segmentos (API). Por meio de um estudo de caso buscamos desenvolver uma investigação das conexões entre pesquisas, crescimento econômico e geração de inovações. A solução de problemas que demandem inovação requer uma inter-relação entre esses agentes.

O potencial de crescimento econômico pode ser catalisado por políticas de fomento, por algum período, mas para que encontre um suporte de sustentabilidade necessita de incorporação contínua de novas tecnologias, de novas soluções para problemas da produção, distribuição ou comercialização, e de agregação de valor baseada em novos produtos, processos, sistemas ou serviços. Analogamente o desenvolvimento social necessita de aporte de novos conhecimentos e soluções para problemas sociais introduzidos ou agravados pela dinâmica da sociedade. O desenvolvimento social e o crescimento econômico necessitam de um esforço continuado de pesquisa científica, com a geração de inovações (sociais e tecnológicas) para concretizar este desenvolvimento e crescimento (TIRONI, 2005; PABJAN, 2004), catalisado pelo fluxo - por meio de difusão, convecção e transferência - de conhecimento (PIETROBONCOSTA et al., 2009), ou inovação, entre grupos sociais e econômicos.

Analisamos a variação do Produto Interno Bruto (PIB) do Brasil e da Bahia, comparativamente aos indicadores de produção científica e de inovações, buscando verificar correlações entre o crescimento econômico, a geração de conhecimento e a pesquisa científica, e a evolução da inovação, traçando um panorama por série temporal da relação entre os AMDI e suas influências inter-relacionadas, focando análise no caso brasileiro e baiano.

\subsection{Inovação e produção científica: interação com o capital?}

Em que pese o aumento significativo da produção científica de pesquisadores brasileiros, o esforço nacional - majoritariamente público, com investimento de 1,02\% do PIB, em 2006, e de 1,4\% do PIB, em 2008, e em menor magnitude privado, $0,51 \%$ (2006) e $0,64 \%$ (2008) do PIB, idem (BRASIL, 2007) - em pesquisa científica, ciência, desenvolvimento tecnológico e inovação (PDI ou PCDTI) ainda não foi suficiente para a geração do conhecimento e da inovação tecnológica com potencial de desencadear impactos importantes para o desenvolvimento econômico do Brasil (SUGAHARA; JANNUZZI, 2005).

A lógica de ação estratégica dos AMDI é a expansão e acumulação de capital, que em uma sociedade de conhecimento é condicionada pela busca do nível ótimo de investimento em novas tecnologias, em pesquisa e em inovação, como componentes das novas estratégias de produção, e da geração e difusão de conhecimento, o mais importante componente, atualmente, do capital das empresas (DE LA MOTTE, 2001). Neste contexto, em uma economia nacional, como a brasileira, em que a presença de corporações multinacionais e transnacionais é significativa, enquanto subsidiárias de empresas originárias nas potências centrais, majoritariamente Europa e Estados Unidos, além de países asiáticos, o maior esforço de PCDTI e integração entre o sistema economicamente produtivo e instituições de pesquisa (GUEDES; FORMICA, 1997) é efetuado nas empresas e países sede destas corporações, resultando em reduzido vínculo entre empresas e ICTs, e no baixo nível de integração de empresas privadas com o esforço de pesquisa e transferência de tecnologia originadas de ICTs.

Porém, mesmo sem desencadear, ainda, impactos importantes, os investimentos em PCDTI contribuem para um desenvolvimento sustentável, ao mesmo tempo que diminuem a necessidade de se comprar conhecimento ou investir recursos em transferência de tecnologia, contribuem com a elevação do PIB 
pela aplicação de novas técnicas e processos, mais eficientes, nos sistemas produtivos, com a oferta de novos serviços e novos produtos. Segundo Cavalcanti (apud RASCHIATORE; MOREIRA, 2006, p. 518), sustentabilidade significa

[...] a possibilidade de se obterem continuamente condições iguais ou superiores de vida para um grupo de pessoas e seus sucessores em dado ecossistema.

Não é fácil estabelecer quais critérios devem ser considerados para definir se há desenvolvimento ou não. Para Sen (apud RASCHIATORE; MOREIRA, 2006, p. 517), não existe consenso entre os cientistas sociais sobre o significado de desenvolvimento, muitas vezes confundido com crescimento econômico. Mas há de se convir que o crescimento da economia seja um dos fatores que contribuem para o desenvolvimento de uma sociedade.

Para Porter (apud MOTA, 1999), à medida que se alcança maior grau de interdependência econômica, política e tecnológica, a inovação tecnológica passa a ser um elemento-chave da competitividade nacional e internacional (WU, 2012), podendo se afirmar que a competitividade de uma nação depende da capacidade de inovar de seu sistema de ICTs, de PCDTI e de seu sistema produtivo.

No Brasil, como em outras potências emergentes e países dependentes, os investimentos em PCDTI ocorrem, principalmente, nas universidades públicas e algumas poucas empresas públicas. Empresas privadas tendem, no Brasil, a apresentar reduzido investimento em pesquisa científica, priorizando a contratação de tecnologia e mais recentemente inovações, em geral de origem estrangeira. Os investimentos tendem a ser regionalizados e há concentração destes em conglomerados de produção (SIMÕES et al., 2005; CAVALERI, 2011). Segundo Mota (1999), a eficiência de um sistema de inovação depende da interação entre vários subsistemas, no caso, os AMDIs. Neste sentido, uma atenção especial deve ser dada ao conceito de inovação.

\subsection{Inovação: do que se trata?}

Segundo Hollanda (2007) e Houaiss (1993), inovação é "o ato, ação ou efeito de inovar", de introduzir novidades, ou seja, a disponibilização para um grupo ou para toda a sociedade daquilo que é visto recentemente ou pela primeira vez. Houaiss aprofunda a definição e considera como inovação "a introdução de alguma novidade nos costumes, na ciência, nas artes, e em campos não associados à produção econômica". Estas definições especificam ser a "inovação" a introdução de uma novidade até então não vista ou percebida, de caráter inédito, portanto, em qualquer dos campos da ação ou de atividade humana.

A Lei Federal 10.973 de 2 de dezembro de 2004 define estes conceitos, in verbis, em seu artigo $2^{\circ}$ como:

- "II - criação: invenção, modelo de utilidade, desenho industrial, programa de computador, topografia de circuito integrado, nova cultivar ou cultivar essencialmente derivada e qualquer outro desenvolvimento tecnológico que acarrete ou possa acarretar o surgimento de novo produto, processo ou aperfeiçoamento incremental, obtida por um ou mais criadores;" $e$

- "IV - inovação: introdução de novidade ou aperfeiçoamento no ambiente produtivo ou social que resulte em novos produtos, processos ou serviços."

O Manual de Oslo define inovação como a introdução em nova tecnologia em produto ou processo com características aprimoradas ou com modificações substanciais, oferecendo ao consumidor ou à empresa um diferencial e ganho significativo (ORGANIZATION..., 2007).

Restringe-se, na Lei 10.973 , inciso II, a definição de criação e de inovação àquelas ações associadas com o desenvolvimento tecnológico ou com o aperfeiçoamento da produção industrial, sistemas computacionais e organismos vegetais geneticamente modificados. Estas três modalidades de inovação embutindo ganhos econômicos industriais. Analogamente, a definição do manual de Oslo restringe inovação a aperfeiçoamento efetuado sobre produto ou processo. No inciso IV, estende-se esta definição de inovação à introdução de novidade ou aperfeiçoamento ao sistema ou organização social. No caso do sistema produtivo, a inovação se encontra, por estas definições, associada a um ganho de capital ou lucro. No caso do sistema social, a lei e as definições são omissas acerca de qual vínculo, e sobre como se dá o benefício da inovação ou sua apropriação.

Verificamos nestas definições da legislação, e na própria preocupação em sistematizar os conceitos e relações associadas à criação e à inovação, a concentração do enfoque normativo legal ao aspecto tecnológico da inovação, na Lei de Inovações, e no conjunto de demais instrumentos legais - decretos, portarias, normatizações - a esta associada.

No sentido restrito de inovação, para a legislação atual, a inovação tecnológica aborda o aspecto conceitual de introdução de alguma novidade na produção desenvolvida por produtores econômicos. A inovação tecnológica foca a criação de novos produtos, processos ou serviços, no panorama postulado pela legislação, e nas ações desenvolvidas pelos órgãos governamentais, pelos Núcleos de Inovação Tecnológica/Escritórios de Transferência de Tecnologia (NITs/ETTs) e pelas instituições de 
ciência e tecnologia (ICTs). Esta abordagem analisada do ponto de vista epistemológico determina a carência de preocupação com inovações não associadas ao desenvolvimento de novos produtos, processos ou serviços, como as inovações de caráter social, de tecnologia social, de caráter cultural, até mesmo na ciência e naquelas de caráter ambiental. Fica assim prejudicada a reivindicação de salvaguardas legais destas inovações - não associadas à produção econômica - e determinada sua exclusão das preocupações e das ações do Sistema Nacional de Propriedade Intelectual, SNPI. Se por um lado dificulta, quando não impede por abstenção, a salvaguarda de direitos de apropriação ou de autor associados a estas inovações, por outro determina uma não valorização, pela legislação, deste aspecto criativo para o sistema industrial e para as organizações sociais. Paradoxalmente, por não valorar inovações que não possam ser associadas diretamente à tecnologia de produção econômica, como o conhecimento por povos indígenas de princípios ativos de fármacos da Floresta Amazônica, o SNPI impede assim que este valor seja computado claramente como capital intelectual ou técnico dos mesmos agentes econômicos. No caso desses fármacos, a estimativa de valor comercial é da ordem de US\$1,73 trilhão (PIETROBON-COSTA, 2010); motivo suficiente para que o conhecimento tradicional correlato seja tratado como uma novação, sendo objeto de patenteabilidade.

A valoração de uma inovação, pelo enfoque da atual legislação, está associada ao quanto pode gerar de lucro ou ganho de capital, e a quanto esta vale em termos do investimento de recursos de capital e equipamentos. A salvaguarda de direitos de propriedade intelectual ou o licenciamento de patentes são os mecanismos de negociação de valor de uma inovação. Considerando estes dois aspectos e a restrição do conceito de inovação às tecnologias de desenvolvimento de novos produtos, processos, sistemas ou serviços, a exclusão ou a atual não consideração de outras inovações pela legislação restringe o estabelecimento de valor às inovações que estejam fora do espectro de desenvolvimento da produção econômica ou lucrativa. Tal é o caso da produção científica realizada por pesquisadores e cientistas nas ICTs. Trata-se de um descaso, epistemologicamente derivado do conceito de res publica associado ao conhecimento científico. Este descaso fundamentado no que para nós assemelha-se a um equívoco, age como uma restrição. Juntamente com o descompasso de interesses e falta de integração entre a produção econômica e a atividade científica, tratar os resultados da produção científica como produtos de domínio público desestimula a preocupação das ICTs e de pesquisadores destas ICTs em buscar salvaguardar o conhecimento científico que geram. O conhecimento, para ser objeto de esforço de geração de patente ou registro precisa ser percebido como uma inovação e, principalmente, estimular um ganho potencial para os pesquisadores, além do simples mérito ou reconhecimento de autoria na geração do conhecimento.

Pesquisa na base de dados do INPI indica que de $1^{\circ}$ de janeiro de 1979 a 31 de maio de 2009 um total de 402.968 depósitos de patentes e modelos de utilidade foram efetuados naquele escritório, dos quais 17,8\% ou cerca de 71.700 são originários do Brasil. Destes somente 2.481 ( $0,62 \%$ do total) tiveram como origem universidades (inclusive privadas). É importante destacar que no caso de patentes nacionais estas se referem a depósitos, ainda não objeto de emissão de cartas patentes, enquanto as de origem estrangeira tratam de patentes já vigentes, as quais são depositadas no Brasil para salvaguarda em território nacional. Tal resultado é um indicativo da baixa sinergia entre as ações efetivas das universidades brasileiras e ações de agregação de valor econômico ao conhecimento. Inovar demanda novo esforço de desenvolvimento na forma de produtos, processos e demais direitos patenteáveis, além do esforço de elaboração da documentação para depósito no escritório nacional de propriedade industrial e intelectual, no caso do Brasil, o INPI, além da gestão da inovação e recursos financeiros para a manutenção do privilégio de exclusividade do direito à patente. Tal esforço vai além do já demandado na pesquisa e encontra-se atualmente além da competência da maior parte das ICTs, dos grupos de pesquisa, e pesquisadores. No caso das ICTs, pela carência de pessoal especializado em elaboração, legislação e procedimentos de patenteamento e registros de propriedades intelectuais. Além deste aspecto, a necessidade de dispêndios financeiros para quitação das taxas anuais de privilégio de exclusividade na exploração ou comercialização da patente onera os pesquisadores, para o que não há fomentos disponíveis nos órgãos de fomento nacionais ou estaduais, gerando desinteresse na manutenção da patente pela maior parte dos pesquisadores. Os programas stricto-sensu também não capacitam seus doutorandos e/ou mestrandos em PI. No caso de pesquisadores, pelo enfoque na formação profissional, não direcionada para este fim, apropriação de inovação ou PI. Sendo a PI uma área específica, transcende o papel da maior parte dos pesquisadores. A PI exige vínculo com o mercado e um processo de gestão de conhecimento, relacionamento com mercado e fornecedores, percepção de nichos de interesse da sociedade, comercialização e licenciamento de patentes, e vinculação da pesquisa aplicada a interesses da sociedade. Este papel precisa ser incorporado pelos NITs e ETTs, ou por meio de construção de equipes multidisciplinares formadas para estas ações, ou por meio do estabelecimento de Parques Tecnológicos responsáveis por mecanismos de transferência de inovações para a sociedade. 
No sentido de buscar estabelecer uma base inicial de elaboração sobre a valoração de inovações sociais e da produção científica de pesquisadores, abrangendo análise de impacto da salvaguarda do conhecimento científico como direito de autor em igualdade com as demais categorias de patentes e registros de privilégios autorais, é necessário correlacionar e fomentar o compromisso individual de pesquisadores ou grupos de pesquisa por meio de sua produção científica com o crescimento econômico e o depósito de registros de patentes. A retribuição pelo esforço de pesquisa, e não somente pelo mérito, é o caminho para este estímulo. O fortalecimento dos NITs e ETTs - não como estruturas burocráticas cartoriais, papel da maioria destas estruturas nas ICTs atualmente, e sim como organismos de fomento a PI e gestão de conhecimento e de PI e, principalmente, de relacionamento com o mercado, empresas e o tecido social - pode vir a ser a via que permitirá aos pesquisadores serem remunerados pela geração de conhecimento objeto de inovação.

\section{Agentes motores de desenvolvimento e inovação}

Conceituamos como produtores econômicos (principais) todas as organizações, em geral com fins lucrativos, que ofertam ao mercado ou à sociedade produtos, bens de consumo, de capital ou equipamentos, serviços, produtos agropecuários, e matérias-primas. Os setores primário, secundário, e terciário da economia englobam estes produtores econômicos. São eles os principais responsáveis pela formação do PIB da sociedade. Considerando as atividades de produção dos trabalhadores, e a devida às atividades governamentais, atingimos a totalidade dos parceiros sociais integralizadores, em valor, do PIB. Porém estes últimos atores são também condicionados em suas atividades pelos produtores econômicos principais.

Os diferentes saberes, o da produção industrial e o do conhecimento científico, estão ambos associados ao potencial de geração de uma forma de ganho. O primeiro, como inovação tecnológica (conforme a atual legislação), um novo produto, sistema ou processo que integra conhecimentos, técnicas e tecnologia, bem como outros novos processos, sistemas ou produtos (como os microcircuitos de um microprocessador). O segundo, na forma da elaboração de conhecimento inédito de caráter social, ambiental, biomédico ou tecnológico (como a corrente elétrica, a teoria atômica, a cirurgia cardíaca, ou a purificação do silício), não necessariamente vinculado à disponibilização de um novo processo, produto, sistema ou serviço. $\mathrm{O}$ conhecimento vinculado à produção industrial encontra respaldo para sua valoração na legislação internacional e nacional por intermédio do depósito de patente, o que não ocorre com o conhecimento puramente científico, sem respaldo legal no processo de salvaguarda autoral, e que tem restringida a possibilidade de avaliação de seu valor comercial. O conhecimento vinculado à pesquisa nos diversos campos da ciência é, em sua maior parte, não diretamente vinculado à produção de bens, produtos, sistemas, mercadorias, processos ou serviços. Porém a inovação tecnológica, como atualmente conceituada só pode ser alcançada a partir do conhecimento elaborado pela pesquisa científica em um sistema de rede de PCDTI (ZAHRA; GEORGE, 2012; CALIA; GUERRINI; MOURA, 2007).

Os produtores de conhecimento no Brasil encontram-se majoritariamente incorporados à produção científica, nas universidades e institutos de pesquisa públicos, e em muito menor número em instituições privadas que também elaborem conhecimento científico. Estes agentes de produção de conhecimento não são atualmente no Brasil os principais geradores de inovações. Assim, cabe papel de destaque em PI às empresas, principalmente as públicas, e não às Instituições de Ciência e Tecnologia (ICTs), tais como as universidades.

A inovação social pode ser entendida como a introdução do novo, com caráter de aperfeiçoamento, na estrutura organizacional e seus mecanismos de relacionamento entre pessoas, nos sistemas de remuneração, nos sistemas de comunicação, e no comportamento, crenças e valores, bem como na percepção e interpretação de missões e visão de futuro das pessoas, profissionais e/ou organizações.

Neste marco, por API designamos os setores especializados que desenvolvem ações direcionadas à integração da inovação tecnológica e social à sociedade. A pesquisa científica e o desenvolvimento de tecnologias constituem-se em atividades complexas, altamente especializadas. Isto exige de todos os seus integrantes uma dedicação extrema na busca de descobertas inéditas. Porém esta dedicação é direcionada a finalidades distintas, ainda que complementares: pesquisa ou inovação. Este panorama dificulta uma aproximação do pesquisador com o setor produtivo, tornando necessária a existência de um órgão especializado que realize essa intermediação.

\subsection{Produtores econômicos principais}

Inovação, ousadia, competência, criatividade e apropriação do conhecimento (SLACK; CHAMBERS; JOHNSTON, 2008) são componentes determinantes no sucesso das organizações, estando no centro do processo de agregação de valor aos seus resultados e produção. Por meio destes componentes, é possível: maximizar eficiência à produção, agregar valor ou elevar a qualidade de bens, trabalho, serviços e produtos, e criar novos processos, bens, serviços e produtos. A Propriedade Intelectual (PI) agrega, 
a esses componentes, mecanismos de apropriação de direitos ou privilégios de exclusividade no uso, industrialização, exploração e comercialização, assegurando proteção à criação e inovação (MUSCIO; QUAGLIONI; SCAPINATO, 2012).

É a PI que cria o diferencial que caracteriza as organizações líderes e as bem-sucedidas, destacando-se pelo desenvolvimento tecnológico de ponta. Esse sucesso é mensurável pela permanência e inserção destas organizações em um mercado em que a concorrência é permanente e a cooperação com outros agentes econômicos e sociais garante: (i) a sustentabilidade do desenvolvimento destes agentes; e (ii) a sustentabilidade de suas ações com relação à sobrevivência no mercado. A aplicação de conhecimentos, no sentido lato, e de inovações, no sentido strito, são os dois fatores-chave destas sustentabilidades que precisam ser dinamizados de forma integrada: (a) o fomento e apoio dos produtores econômicos ao aperfeiçoamento e capacitação de seus profissionais - via PCs e/ou APIs - bem como a retenção deste capital intelectual; e (b) o estímulo à ousadia, criação e empreendedorismos individual (ou de equipes) e/ou a ação conjunta PEs \& PCs no sentido de que a PCDTI resulte na inovação e na propriedade intelectual.

A indústria, no sentido amplo, concentra os equipamentos, os materiais, o capital, a mão de obra e o conhecimento, no sentido do desenvolvimento da produção e maximização da eficiência operacional. O conhecimento no sentido do saber fazer é utilizado especificamente pelo setor produtivo para introduzir aperfeiçoamentos em produtos e processos, e atender às demandas necessárias de cada etapa da produção. Isso caracteriza o diferencial que garante a permanência da organização no mercado. Para que um novo produto, processo ou sistema seja inserido como diferencial na cadeia produtiva é preciso que haja incorporação de conhecimento científico inovador na forma de novos componentes integrados neste novo produto, sistema ou processo.

Há um novo padrão de acumulação no mundo em que se percebe o aumento da complexidade dos conhecimentos desenvolvidos pela pesquisa científica e acelera-se a incorporação de conhecimentos aos bens, produtos, sistemas e serviços produzidos e comercializados na sociedade humana (LOIOLA; RIBEIRO, 2005).

As atuais maiores economias do planeta, as economias centrais, apresentam concentração de pesquisadores responsáveis pela geração de conhecimento inovador em suas unidades de pesquisa vinculadas à produção da indústria e a serviços, ou em segmentos universitários associados à pesquisa fomentada pelo setor industrial principalmente. São estes pesquisadores que desenvolvem as inovações e aperfeiçoamentos geradores de patentes e registros de PI.
No Brasil, entretanto, esta base de conhecimento, os pesquisadores, tem sido formada e fixada ao longo dos anos nas universidades, especialmente nas públicas e em poucas instituições privadas que efetivamente desenvolvem pesquisa científica, pesquisa desvinculada, majoritariamente, das expectativas dos produtores econômicos. A causa desta dicotomia é o baixo investimento do setor produtivo em inovações, e salvo exceções, a queda de competitividade frente à concorrência internacional. Usualmente, na indústria brasileira, a introdução de inovações se dá por aquisição de máquinas e equipamentos ou aperfeiçoamento de processos, com base em conhecimento de origem externa à organização, geralmente no exterior, acompanhando o desenvolvimento de empresas concorrentes, mas não estabelecendo um diferencial à frente destas, pela ausência de exclusividade ou privilégio na propriedade intelectual da inovação.

A nova Lei de Inovações, Lei 10.973 de 2004, vem buscar, legislando sobre o tema, fomentar a parceria entre Instituições de Ciência e Tecnologia (ICTs) - pesquisadores - e a indústria, para acelerar a geração de PI no Brasil. Os mecanismos e estímulos disponibilizados pelo que pode ser denominada de Política Nacional de Ciência, Tecnologia e Inovação agem então no sentido de, via o estímulo a esta parceria, ICTs - PEs, romper com a lógica de importação de tecnologias, fomentar a incorporação de conhecimento em produtos, processos e serviços, gerando inovação, resultando em apropriação do conhecimento inovador para o meio de processos de PI.

\subsection{Produtores de conhecimento}

A literatura especializada tem comprovado o papel da universidade como uma importante fonte $\mathrm{e}$ repositório de ciência pública, de conhecimentos, e na formação de capital humano (NELSON, 1992). A pesquisa acadêmica é fonte de conhecimentos para o avanço tecnológico. Políticas públicas nas economias centrais têm catalisado e fomentado a interação entre ICTs e produtores econômicos principais (MOWERY; SAMPAT, 2005), estimulando a transferência de conhecimentos tecnológicos das ICTs para o setor produtivo. $\mathrm{O}$ crescimento das patentes de origem universitária é uma realidade, com elevação em taxas superiores às do setor produtivo privado, mesmo em potências econômicas.

Agente social de formação de recursos humanos, de formação avançada de pesquisadores e cientistas, a universidade destaca-se como agente de transferência de conhecimento; sendo, o conhecimento, o elemento fundamental do capital intelectual, as ICTs indiretamente geram conhecimento que permite a consecução de inovações. Estas, por sua vez, se destacam, portanto, como motores de desenvolvimento, 
conhecimento aplicado na forma de novos sistemas, produtos, processos, e serviços Além de formar profissionalmente cidadãos, contribuem para a geração do conhecimento e a criação de inovações por meio da pesquisa. Cabe ao ensino superior a formação de profissionais com especializações avançadas específicas para os setores de atividade da sociedade. É possível ainda a capacitação de seus pesquisadores para atuarem em inovação, condicionada à preservação de suas atividades fins. O papel da universidade é generalista no sentido de formação da mão de obra especializada e, específica no sentido do desenvolvimento do conhecimento e do saber fazer, isto é, da pesquisa científica, além da inovação em áreas apropriadas das ICTs.

Para desenvolver eficientemente este segundo papel, é importante que a universidade esteja aparelhada adequadamente, intelectual e materialmente. Tanto com foco no avanço estratégico (alavancagem de desenvolvimento sustentado, econômicos, social e ambiental), como com foco operacional (via integração com empresas ou gestando-as em parques tecnológicos associados, transformando conhecimento em inovação), e no nível tático ou de atividades fins (capacitação de pesquisadores e grupos de pesquisa para apropriação do conhecimento e ações de PI). Este é o pré-requisito para que as universidades elaborem novas ideias, desenvolvam tecnologia quando associadas com PEs e gerem conhecimento nas diversas ciências. A performance de uma nação e de uma economia nacional em termos de inovação e produtividade é resultado não só do investimento (público e privado) em PCDTI, mas principalmente devido às conexões indústria-academia, e a uma eficiente gestão em PCDTI e PI (ALBUQUERQUE et al., 2011; DEBACKERE; VEUGELERS, 2005) da qual resulta o sucesso da nação quanto a estes critérios. Eficiente governança em transferência de tecnologia e conhecimento e uma estrutura ágil de gestão, concretizada nos Núcleos de Inovação Tecnológica, NITs, e nos Escritórios de Transferência de Tecnologia, ETTs, são peças-chave desta conectividade entre a academia e o setor produtivo. Estes organismos têm sido projetados usualmente em uma mesma estrutura, acumulando funções, cabendo-lhes serem integradores do conhecimento, promotores de conhecimento, de inovação, e desempenho econômico. No entanto, ainda hoje, a produção de conhecimento nas universidades atende ao perfil e está em sintonia com as características dos pesquisadores nela inseridos. Caberá então aos NITs e/ou ETTs capacitar os pesquisadores também em inovação PI, gerir a política de inovação em sua ICT, fomentar, fortalecer e consolidar as conectividades e diálogo quanto a PI entre a academia e os produtores econômicos principais.

Trata-se de uma ação que poderia ser avaliada como extensionista, porém não o é. Por agrupar contribuições da pesquisa científica, da formação de recursos humanos e de transferência de produção acadêmica, os NITs/ETTs são na verdade uma estrutura orgânica de integração do trinômio Ensino, Pesquisa e Extensão (EPE), no qual se alicerça a filosofia organizacional da universidade brasileira. Por falta de um canal eficiente de comunicação com os diversos outros segmentos e setores integrantes da sociedade, a universidade carece de resposta ágil às demandas e anseios por soluções dos problemas sociais, de produção, e estruturais da sociedade. Os NITs/ETTs seriam esta estrutura, quanto à inovação. A Lei Federal de Inovações e a Lei de Inovações do Estado da Bahia propõem que as ações dos NITs/ETTs sejam efetivadoras do papel de API. Entendemos haver aí um conflito de atribuições que pode comprometer o bom resultado das ações de PI e PCDTI das ICTs. Encontra-se além do papel destes organismos serem APIs. Os NITs são organismos de gestão em PI e capacitação interna da ICT. Cabe aos ETTs serem responsáveis pela conectividade da ICT com o sistema de produção da sociedade, os PEs. Então estes organismos, NITs e ETTs, são integradores em execução das ações do trinômio EPE. Podem, se bem coordenados em suas atividades, estabelecer o diálogo ágil e rápido de propostas de soluções para problemas estruturais ou dinâmicos da sociedade, capacitar recursos humanos em inovação, fundamentar ações de apoio e incubação apoiadas em soluções inovadoras, salvaguardando as patentes geradas na ICT a que sejam vinculados, e disponibilizando este conhecimento para a sociedade por meio de transferências de tecnologia, de inovações e de conhecimento aplicado. Esta política pode ser efetiva quando conduzida por profissionais especializados, experientes em pesquisa, geração de conhecimento e inovação, dedicados a encontrar canal de inovação e canal de fluxo eficiente de inovações com a sociedade. A integração dos NITs e ETTs de cada ICT necessita então ser efetuada por um organismo gestor. Tal organismo é o integrador das ações destes, uma Coordenação de Inovação da ICT, um API.

\subsection{Agentes de Apropriação de Inovações, ou Agentes de PI (API)}

Empresas e organização que não inovem fatalmente irão sucumbir: desaparecerão ou se tornarão obsoletas. Todos os que necessitem se envolver com projetos, planejamento, solução de problemas ou desenvolvimento de soluções, ainda que não sejam atividades imediatamente criadoras com radicais alterações ou aperfeiçoamentos sobre o já existente, necessitam de inovações ou necessitam inovar (TOMALA; SÉNÉCHAL, 2004). Porém inovar causa resistências, sobretudo em entidades conservadoras, superdimensionadas ou que possam perceber a 
ação ou gestão inovadora como um acréscimo nas responsabilidades setoriais ou departamentais. Cabe aos APIs romper essa resistência pela informação aos pesquisadores e técnicos da ICT quanto aos benefícios da inovação e/ou da ação de inovar. Cabe aos APIs além dos objetivos de salvaguarda de PI e transferência de tecnologia e conhecimento inovador, sensibilizar internamente sua organização, ICT, empresa ou segmento, dos ganhos de recursos e concretizações a alcançar com as inovações. Tais benefícios estão associados com uma agregação de valor diretamente ou potencial de produção ou de pesquisa, possível pela agregação de conhecimento nas inovações. A pesquisa científica e a inovação têm em comum a incorporação de novos saberes, quer na forma ou de artigos e comunicações científicas, quer na forma de patentes e registros de PI. Em ambas as ações, o que se aborda é a difusão de conhecimento. A difusão de conhecimento para fora dos limites da fonte de pesquisa ou inovação resulta em interação com outras fontes de pesquisa e inovação e em expansão da própria capacidade criadora (BEVILACQUA; GALEÃO; PIETROBON-COSTA, 2007; PIETROBON-COSTA et al., 2007). Este resultado é, se não o principal, um dos principais da ação inovadora. No Brasil, com concentração de pesquisadores e da inovação em ICTs, universidade e institutos de pesquisa, ela indica o centro da ação dos APIs nestas instituições. Conectar esta parcela da sociedade, sendo ponte de diálogo, isto é, de adequação de papéis, sensibilização de PEs e estímulo à integração de ações em geração e transferência de conhecimento, inovação e PI, da academia com o setor produtivo, enquanto simultaneamente sensibiliza os pesquisadores das ICTs para a temática inovação, é talvez o centro da atividade dos APIs.

A fonte de diálogo e centro de sensibilização em inovação a que nos referimos não tem passado despercebida. O governo brasileiro, atento ao desenvolvimento da área de PCDTI, incorporou à legislação (Lei Federal 10.973 e Lei Federal 11.487, referentes à pesquisa científica, à inovação e a incentivos em PCDTI) mecanismos de fomento à conectividade das ICTs com o setor produtivo, bem como de estímulo ao processo inovador em associação das ICTs com a indústria e o setor de serviços. Com base neste estímulo, foi acelerado o processo de criação e consolidação dos núcleos de inovação tecnológica (NITs) e dos escritórios institucionais de transferência de tecnologia (ETTs). O papel que nesse processo tem sido atribuído a estas estruturas, NITs e ETTs, é o de construir uma via direta de ligação entre o setor produtivo, sobretudo a indústria e o segmento de serviços, e as ICTs, sobretudo as universidades, levando as inovações e o desenvolvimento tecnológico gerado pela pesquisa para aplicações econômicas. Sem diminuir a importância desta ação, avaliamos que o conhecimento científico gerado nas ICTs abrange em igual grau de importância as áreas de ciências sociais e de ciências humanas, as quais têm respostas, usualmente não merecedoras de destaque pelo setor produtivo, para uma pletora de problemas da sociedade e relacionadas com a relação humana com o meio ambiente. Cabe aos NITs/ETTs também o papel de apoiar as inovações no sentido lato, geradas pelas ciências humanas e sociais, ainda que não valoradas pelo atual perfil da legislação. A incorporação de inovações sociais ao SNPI, e também do conhecimento científico ao processo de valoração, pode ser forte estímulo à produtividade científica e à geração de inovações, com potencial de busca de superação de problemas sociais e ambientais, como a pobreza, a fome, e a extinção de espécies, buscando novas soluções às quais o capitalismo, e a globalização, falharam em solucionar, por não ser objeto de geração de lucro. Exemplo de inovação social são as redes sociais virtuais, que, utilizando as facilidades da Internet, permitem a reorganização de formas de comércio, de redistribuição de espaços de trabalho, expansão da interação e taxa de comunicação entre profissionais, viabilizando reorganização de relações produtivas, a geração de lucro, e expansão da velocidade de acumulação de capital.

\section{Resultados e conclusões}

Nossa investigação considerou os valores e a variação quantitativa de dados relativos ao Estado da Bahia e ao Brasil. Consideramos análises desenvolvidas sobre o Produto Interno Bruto (PIB) da Bahia e do Brasil comparativamente aos dados quantitativos de produção científica e de concessões de patentes, além da agregação de valor à pauta de exportações, buscando observar sua evolução, sob uma ótica interconectada, em séries históricas.

O PIB foi utilizado como parâmetro de análise do crescimento econômico, considerando-se que ele está diretamente relacionado aos produtores econômicos, um dos três agentes motores de PI. Tomamos o PIB e o percentual de manufaturados e industrializados no comércio exterior como referência de crescimento econômico, pois, segundo Lima e Domingues (2000), a "taxa de crescimento real do PIB é, por si só, insuficiente para se caracterizar se a economia entrou em um período recessivo ou de crescimento." Corrigimos esta avaliação, portanto, pela correlação da variação temporal do PIB com a do comércio exterior e a agregação de valor a este comércio.

A coleta de dados da produção científica foi efetuada no banco de dados do Sistema de Informações sobre Indicadores de Ciência, Tecnologia e Inovação, denominado "Indica", da Fundação de Amparo à Pesquisa do Estado de São Paulo (Fapesp). O sistema 
utiliza as principais bases de dados disponíveis, nos âmbitos nacionais e internacionais para a geração dos indicadores, tais como, a base de dados Science Citation Index Expanded (SCIE) do Institute for Scientific Information (ISI) e Scientific Electronic Library Online (SciELO), da CAPES e do CNPQ. Foram utilizados dados dos relatórios relativos à produção científica e de patentes do Ministério de Ciência e Tecnologia, MCT. Com relação à propriedade intelectual (patentes), as fontes foram os relatórios do IBGE, do INPI e do Ministério de Desenvolvimento, Indústria e Comércio Exterior, MDIC, bem como os relatórios da WIPO, World Intellectual Property Organizatiaons, da ONU. Os dados relativos ao PIB foram obtidos das bases do Instituto de Pesquisa Econômica Aplicada (IPEA) do IBGE, junto ao Banco Mundial, e junto à Superintendência de Estudos Econômicos e Sociais da Bahia (SEI).

A Figura 1 apresenta a curva de variação dos PIBs Brasileiro e da Bahia. A taxa de crescimento do PIB brasileiro é ascendente no período 1995-2010, com exceção dos períodos de 1997 a 1999, período recessivo em que se apresenta estagnado, e de 2008 a 2009, coincidente com a crise internacional de mercados.

Também na Figura 1, percebe-se que o PIB do Estado da Bahia apresenta crescimento reduzido ou estagnação no mesmo período, comparado ao PIB brasileiro. A Bahia ainda não possui uma estrutura econômica expressiva de agregação de valor à sua produção econômica. Historicamente, o setor primário sempre foi a base da economia, mas, desde a década de 1960, a relação da contribuição para o PIB dos setores primário, industrial e de serviços vem se modificando com o crescimento do setor secundário, até a década de 2000, impulsionado pela chegada de várias indústrias de transformação e montadoras, e predominância do setor terciário desde meados do século XX. A Figura 2 mostra esta alteração relativa na contribuição dos três setores à produção econômica da Bahia. É relevante o crescimento do setor secundário nestes decênios.

O PIB do Brasil cresceu 2,64 vezes entre 1985 e 2010, passando de $\mathrm{R} \$ 1.394,2$ bilhões para $\mathrm{R} \$ 3.675,0$ bilhões em valores correntes atualizados, enquanto o da Bahia ascendeu de R \$ 66,1 bilhões (3,732\% do PIB nacional) para R $\$ 142,96$ bilhões $(3,88 \%)$, uma participação percentual aproximadamente estagnada em comparação com o PIB nacional.

Os crescimentos dos setores terciário e secundário da economia explicam o comportamento da modesta expansão econômica da Bahia. A evolução do PIB baiano, contudo, é desacoplada da taxa de crescimento do PIB brasileiro.

Com relação ao crescimento da produção científica, comparamos a produção científica do Brasil e do Estado da Bahia em séries históricas. A Figura 3 mostra a evolução do número de publicações indexadas nas bases SCI e SSCI do ISI.

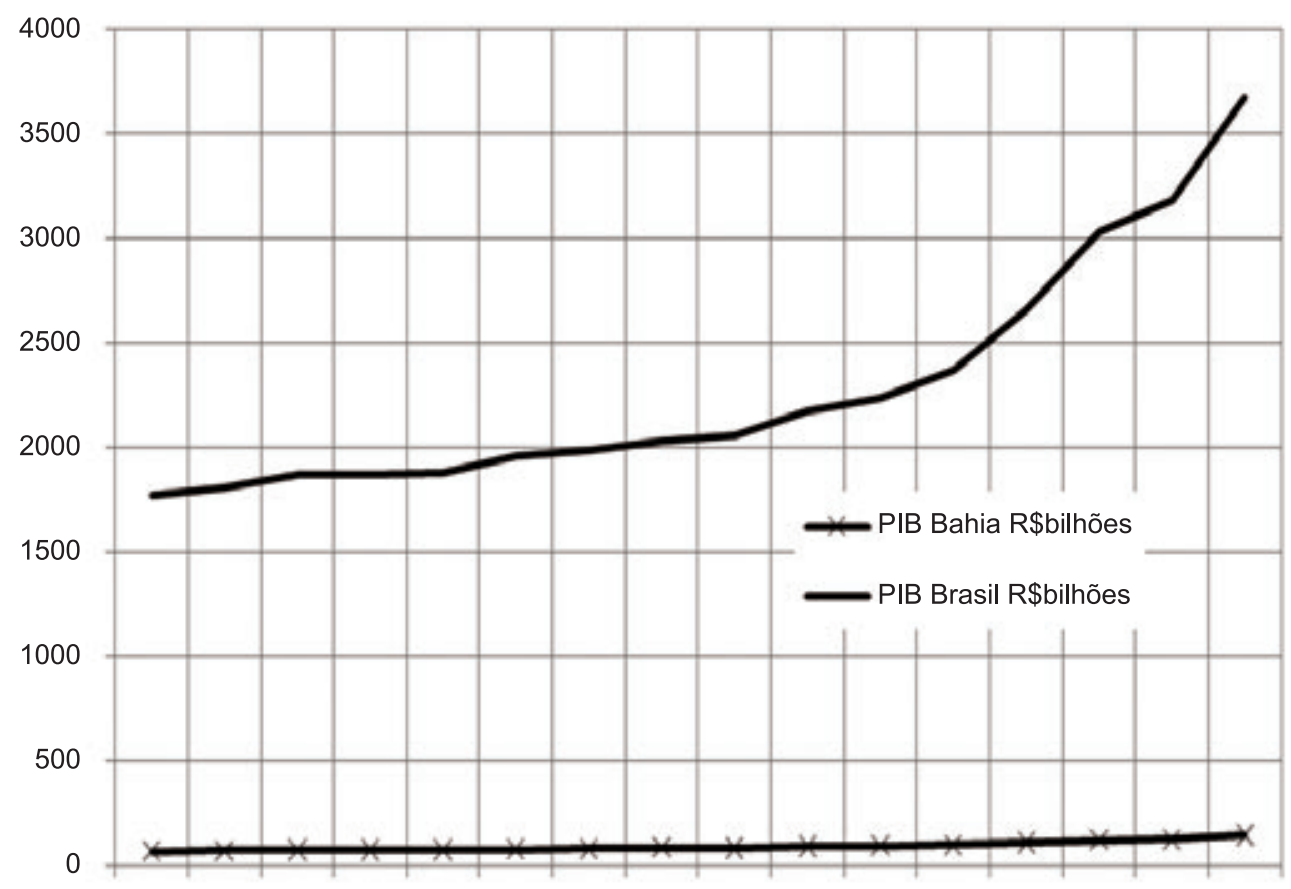

1995199619971998199920002001200220032004200520062007200820092010

Figura 1. Comparação dos PIBs do Brasil e da Bahia (fontes: MDIC e SEI). 


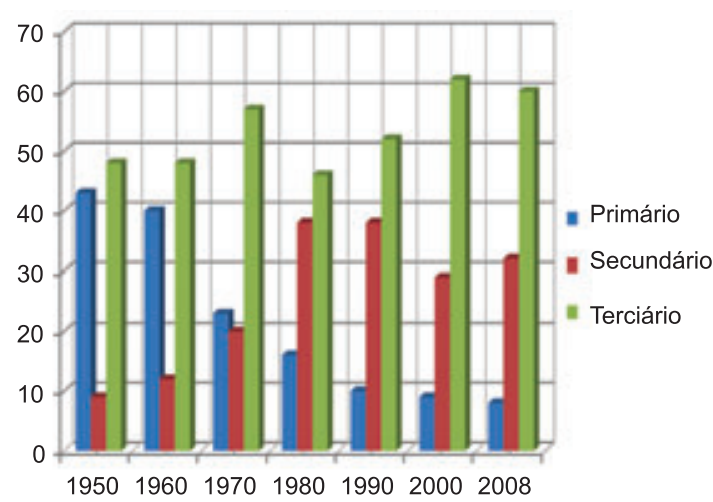

Figura 2. Estrutura Setorial do PIB da Bahia ao longo das décadas (fonte SEI).

A produção científica do Brasil aumentou consideravelmente de 1985 a 2000, com uma expansão de magnitude aproximada de 3,5 vezes em 15 anos. A Figura 4 em contrapartida apresenta uma expansão do número de publicações, originadas da produção de pesquisadores baianos ou radicados na Bahia, de artigos em periódicos científicos indexados, no mesmo período. Até 1995 esta produção manteve-se aproximadamente constante. A partir de 1995 há uma elevação na produção da ordem de 2,5 vezes, i.é, $150 \%$, nestes 15 anos, o que melhor representa a evolução dos investimentos na produção científica baiana e a expansão do quadro de pesquisadores e doutores nas ICTs do Estado. Verifica-se que a elevação na produção científica da Bahia não apresenta reflexos na taxa de evolução do PIB do Estado.

O comportamento histórico do PIB está relacionado fortemente com as exportações (Figura 5). O impacto da participação de produtos industrializados sobre as exportações contribuiu fortemente para a elevação da magnitude do comércio exterior brasileiro (Figura 6). As quedas nas taxas de crescimento, em 2009, são reflexos da crise internacional.

O PIB brasileiro (Tabela 1) elevou-se a uma taxa média nominal acumulada de $13,41 \%$ ao ano entre 1999 e 2007, ainda que considerando um decréscimo de 2000 a 2002. No mesmo período, as exportações apresentaram uma elevação média à taxa de $26,07 \%$, enquanto a agregação de valor às exportações expandiu-se a $23,01 \%$.

Quando correlacionamos a série histórica do PIB brasileiro com a série de mesma ordem relativa à produção científica do Brasil, Figura 7, verificamos que o comportamento de expansão destas variáveis, e de suas taxas de crescimento, é significativamente distinto. Sendo o PIB do Brasil influenciado em seu crescimento pelo comércio exterior e observando uma discrepância entre a expansão deste e da parcela de produtos industrializados exportados com a expansão da produção científica, avaliamos que os produtos

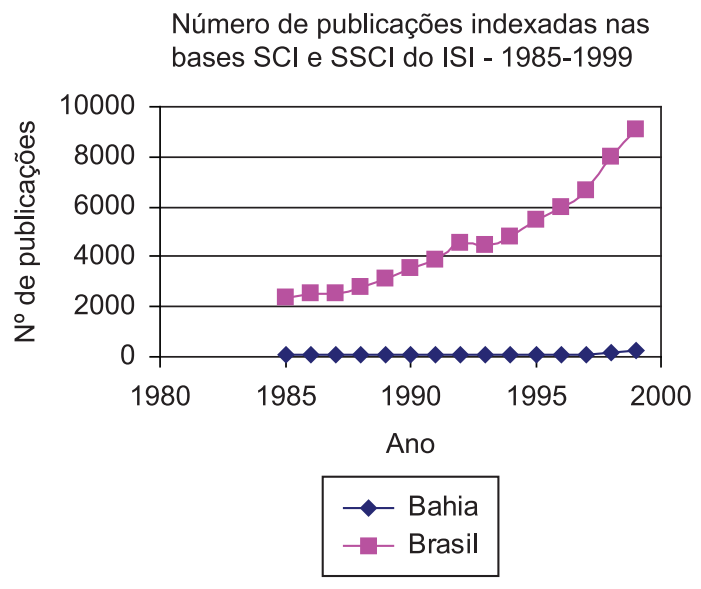

Figura 3. Evolução do Número de Publicações, Brasil e Bahia, indexação no ISI (fonte: Indica, Fapesp).

Número de publicações do Estado da Bahia indexadas nas bases SCI e SSCI do ISI, 1985 1999

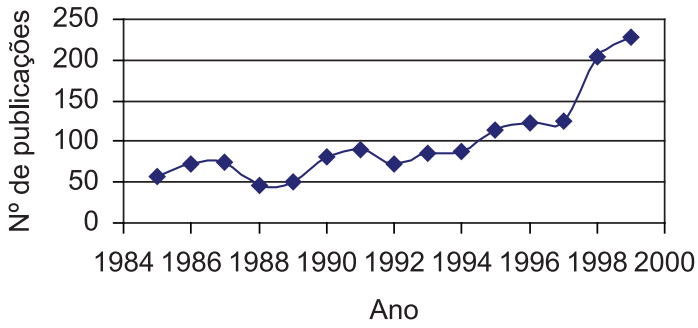

Figura 4. Evolução do Número de Publicações da Bahia indexadas no ISI (fonte: Indica, Fapesp).

brasileiros, ainda que industrializados, encontram demanda internacional devido às necessidades de suprimento dos compradores externos e não pela agregação de conhecimento científico de origem interna a esses produtos. Correlacionando a produção científica brasileira com o depósito de patentes de origem brasileira, Figura 7 , junto ao escritório americano, o que mais recebe depósitos de PI internacionalmente, verificamos uma completa ausência de contribuição da expansão da produção científica brasileira, crescente, com a salvaguarda de PI, depositada naquele escritório.

Há ausência de semelhança também entre o comportamento da série histórica do número de publicações - produção científica - e do PIB no Estado da Bahia. No Brasil, a produção científica cresceu em uma taxa maior que o PIB. Na Bahia, o crescimento da produção científica foi significativamente maior que o do PIB, apresentando curvas de comportamento distinto e mesmo oposto em suas taxas, a partir de 1997 (Figura 8). Este comportamento demonstra uma desvinculação, na Bahia, entre a produção científica e o comportamento do PIB estadual, no período 


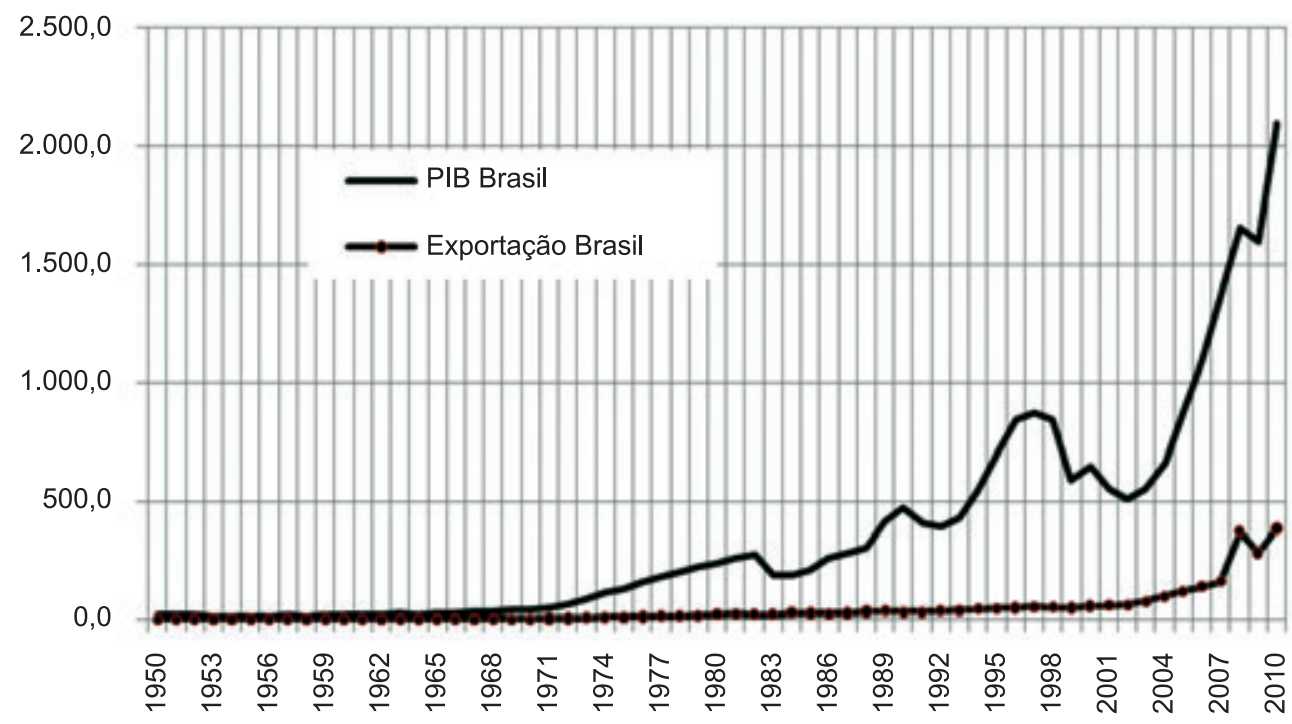

Figura 5. PIB $\times$ Exportações - Brasil, US\$ FOB Milhões (fonte: MDIC).

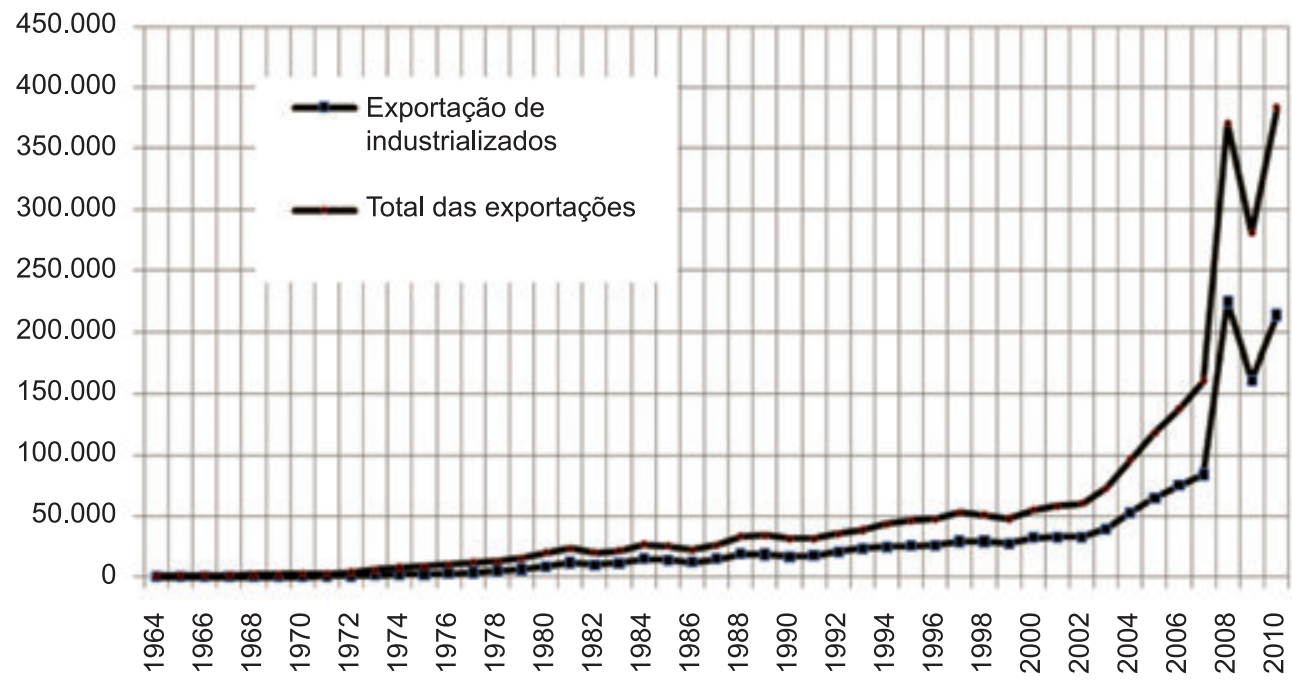

Figura 6. Agregação de valor ao comércio exterior do Brasil, US\$ FOB Milhões (fonte: MDIC).

de 1985 a 2000. Seria de esperar que, ao longo de 15 anos, a produção científica significativamente crescente do Estado da Bahia resultasse, se adequadamente incentivada e apoiada, em incorporação de conhecimento inovador à produção econômica. Isso não ocorreu.

Avaliamos que existe uma ausência de agregação de valor no crescimento econômico verificado nos últimos nove anos, 1999 a 2007, principalmente, por não incorporação da expansão da produção científica no Brasil e na Bahia à produção econômica, como um agregador de valor, na forma de incorporação de inovação a esta produção. Mais significativo é considerar que a expansão da produção científica brasileira ainda não resultou na expansão do processo
Tabela 1. Série histórica de indicadores econômicos (fonte: MDIC).

\begin{tabular}{cccc}
\hline Ano & PIB US\$ & \multicolumn{2}{c}{$\begin{array}{c}\text { Exportações, } \\
\text { milhões US\$ FOB }\end{array}$} \\
\cline { 3 - 4 } & bOB & Industriais & Total \\
\hline 1999 & 586,8 & 27.329 & 48.011 \\
2000 & 645,0 & 32.528 & 55.086 \\
2001 & 553,8 & 32.901 & 58.223 \\
2002 & 504,4 & 33.001 & 60.362 \\
2003 & 553,6 & 39.654 & 73.084 \\
2004 & 663,8 & 52.948 & 96.475 \\
2005 & 882,4 & 65.144 & 118.308 \\
2006 & $1.072,0$ & 75.018 & 137.807 \\
2007 & $1.295,5$ & 83.943 & 160.649 \\
\hline
\end{tabular}


de salvaguarda de propriedade intelectual na forma de patentes. Ainda não podemos afirmar que, no Brasil e na Bahia, o aumento da produção científica provoca o crescimento do PIB e crescimento econômico, com os benefícios sociais daí resultantes. Mas pode-se afirmar que a ausência de conexão entre os agentes de produção econômica, de produção científica e de apropriação de inovações pode resultar na ausência de sustentabilidade da expansão econômica brasileira devido à ausência de agregação de inovações e criação de um diferencial de valoração dos produtos, serviços, sistemas e processos.

A correlação entre taxas de expansão da agregação de valor a produtos de exportação, pelo critério de participação percentual de produtos industrializados apresenta o comportamento dado na Figura 9. A partir de 1984, com a presença de picos pontuais de elevação da participação, o percentual de produtos industrializados na pauta de exportações brasileira tem se mantido aproximadamente constante.

A expansão da produção econômica medida pelo PIB não reflete necessariamente na agregação de valor aos produtos envolvidos no comércio exterior. Por outro lado o crescimento da produção científica brasileira também não encontra correspondência em um esperado crescimento na salvaguarda de propriedades industriais e intelectuais, ou seja, em PI (Figura 7). Tal constatação permite questionar se a ausência de expansão da participação industrial no comércio exterior brasileiro está associada com a ausência de incorporação de inovações, que poderiam corresponder à expansão da produção científica que pudesse gerar maior demanda por produtos, sistemas

\section{Publicações versus PIB Brasil 1985-1999}
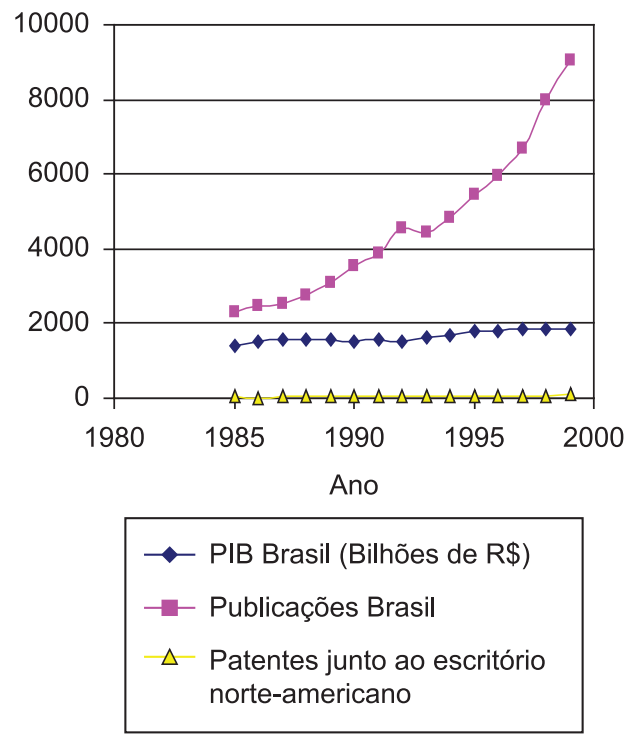

Figura 7. Evoluções do PIB, produção científica e PI do Brasil (fontes: MDIC e Indica, MCT). e processos industriais de maior valor agregado motivador de elevação de interesse ou necessidade de uso por não encontrarem concorrentes no mercado internacional.

Constata-se ainda a ausência de vinculação direta entre o crescimento econômico brasileiro, medido pelo PIB, e a incorporação de inovações geradas pela produção científica nacional ao analisarmos a série histórica do total de remessas ao exterior, em dólares americanos atualizados para 2004, como pagamentos por licenciamentos de tecnologia e serviços correlatos, Figura 10. Observando-se expansão destes pagamentos e ausência de vínculo entre a expansão do PIB e do comércio exterior, com relação à produção científica nacional e na Bahia, verifica-se que o crescimento do PIB e do comércio exterior brasileiro tem se dado, com exceções pontuais, principalmente com base em tecnologia estrangeira, sem base na geração de conhecimento científico ou em patentes nacionais.

O Brasil é o $17^{\circ}$ colocado em investimentos em PCDTI, com 0,97\% do PIB em 2005 e 1,02\% do PIB em 2006 (BRASIL, 2007). De 1981 a 2006, a produção científica nacional experimentou uma expansão de $436 \%$, passando de uma participação na produção mundial de $0,44 \%$ a $1,92 \%$, enquanto o investimento privado em inovações alcançou $0,51 \%$, metade do investimento em PCDTI pelo País; ao mesmo tempo o setor privado participa com $86,1 \%$ do valor total da formação do PIB pelo critério da produção (INSTITUTO..., 2006).

As constatações inferidas para a realidade brasileira como um todo encontram identidade com a realidade baiana em particular. Inovar significará elevar a diferenciação e disponibilidade (pela demanda por funções ou especificidades inéditas) de produtos, bens de consumo, processos, sistemas, soluções sociais,

Publicações versus PIB da Bahia - 1985-1999

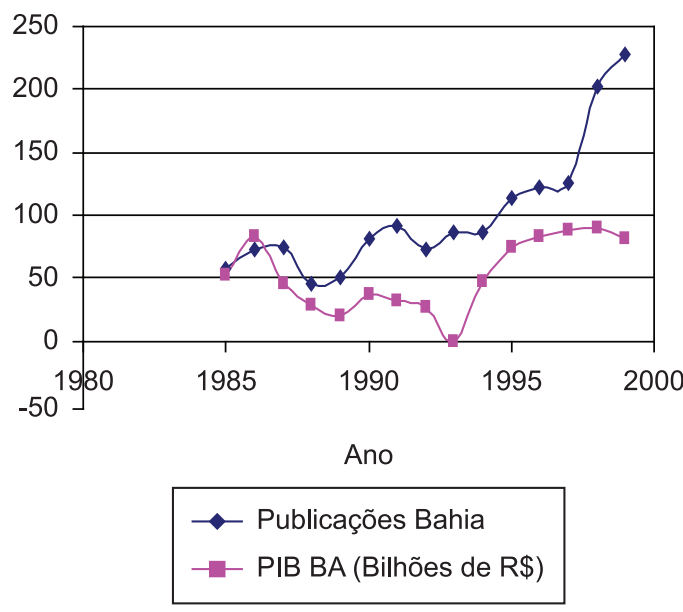

Figura 8. Evolução do PIB e produção científica da Bahia (fontes: SEI e Indica). 


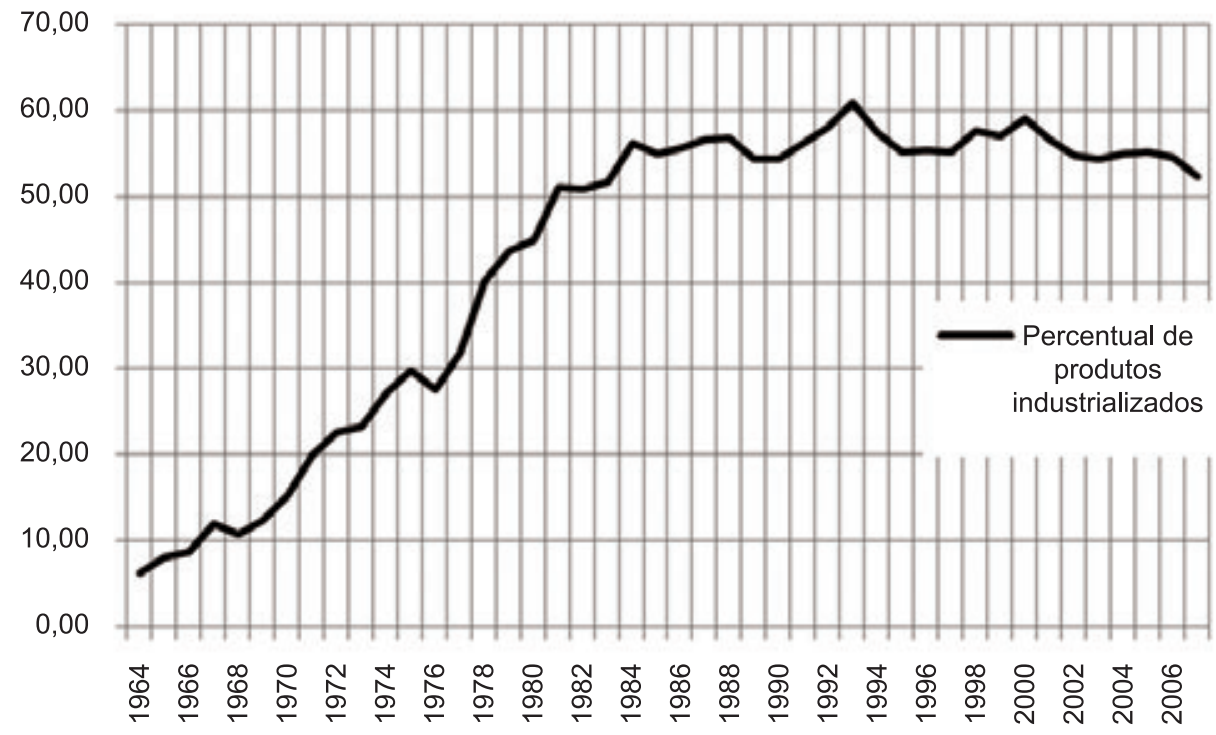

Figura 9. Agregação de valor à pauta de exportações, Brasil (fonte: MDIC).

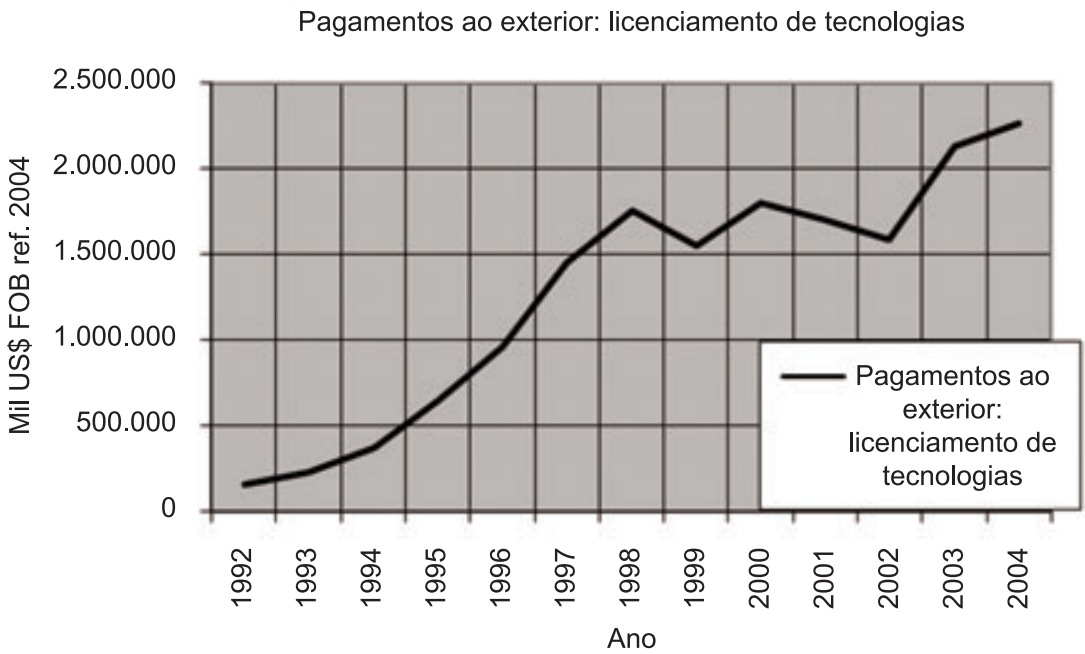

Figura 10. Remessas ao exterior por contratos de transferência de tecnologias e correlatos (fonte: MDIC).

de produção e ambientais. Tal disponibilização de inovações, para produzir bens, sem igual ou equivalente no mercado resulta em elevação da demanda e valoração de novas disponibilidades daqueles. O resultado é expansão econômica e, se bem conduzida, aperfeiçoamento das condições sociais da existência humana. Há, contudo, que cuidar para que esta expansão não resulte em exploração perniciosa de recursos ambientais, em impactos negativos à biosfera. Novamente este cuidado requer inovação também para o sucesso deste processo.

\section{Conclusões}

Não verificamos, no período analisado, indicativos de estar ocorrendo crescimento econômico brasileiro devido ao crescimento da produção científica, e devido à salvaguarda de inovações. Na Bahia, há total descompasso entre a produção científica nas suas ICTs e o desempenho econômico do Estado.

Podemos inferir que os três agentes componentes do desenvolvimento, do crescimento econômico e do processo de inovação dependem de forma interativa uns dos outros. Os AMDI mantêm uma interdependência e não podem se desenvolver por muito tempo de forma independente, considerando que agentes da produção econômica interessados em se fortalecer e tornar-se diferencial com relação a concorrentes necessitam buscar soluções inovadoras no repositório de conhecimentos das ICTs e APIs, sendo necessário que se invista em PCDTI e em PI. 
Para se ter uma economia que cresça sobre bases sustentáveis, é preciso simultaneamente investimentos em PCDTI e ação afirmativa e continuada dos APIs. Atualmente a proporção de investimento nesta área encontra-se desbalanceada com relação à participação pública - privada na composição do PIB nacional. Tomando o índice de 1,02\% do PIB como investimento em PCDTI, coube ao setor produtivo privado (2006) um investimento de $0,51 \%$ do PIB e a diferença percentual ao setor público. Elevar este investimento público a $0,85 \%$ (BRASIL, 2007) tem reflexo no crescimento do valor agregado adicionado no comércio exterior brasileiro (produtos industrializados, agregadores de inovações) e resulta em maior competitividade por incorporação de inovações.

A importância e o papel dos AMDI conectam-se à sustentabilidade do desenvolvimento e crescimento. A comunicação entre os componentes dos AMDI facilita a identificação e aplicação de inovações na sociedade. Inovações no sentido amplo, sejam elas um produto, serviço ou processo, ou inovações no âmbito social, e que não tenham uma preocupação de geração de lucro financeiro.

Quando uma sociedade se expande economicamente sem atentar para o desenvolvimento da pesquisa, e efetuando este investimento em descompasso com o processo de inovação, ela terá que comprar tecnologia e conhecimento de outros lugares. O custo a ser pago, não somente financeiro, geralmente elevado, acaba por tornar essa sociedade dependente de conhecimento alienígena condicionando seu desenvolvimento a know how importado.

Quando uma sociedade busca desenvolvimento social ou uma relação sadia de desenvolvimento com o meio ambiente sem elaborar conhecimento próprio que embuta especificidades inerentes a esta sociedade ou ao seu meio, se torna dependente de soluções que apresentarão inconsistências com aspectos locais, quando não forem conflitantes com estes. O custo a ser pago, sobretudo não financeiro, acaba por tornar essa sociedade descaracterizada por conhecimento alienígena, culturalmente colonizada, tendo seu desenvolvimento condicionado por interesses potencialmente opostos aos interesses nacionais.

Como afirma Cardoso (2004), o isolamento das Universidades, enquanto um dos AMPI, a falta de amparo às pesquisas e a não aplicabilidade dos estudos condenam um país ou estado à submissão tecnológica, e no nosso ponto de vista, também cultural. Mais de dez mil doutores (BRASIL, 2007) têm sido formados por ano sem absorção significativa pela indústria nacional. Há um forte desinteresse do setor economicamente produtivo nacional em investir em geração de conhecimento e em inovação, dando preferência à importação de tecnologia.

É imprescindível, nesse contexto, que os governantes brasileiros, assim como os baianos, percebam a correlação existente entre desenvolvimento social, crescimento econômico, e desenvolvimento científico.

Os resultados aqui expostos ainda não demonstram um crescimento suficiente no papel do binômio pesquisa científica - inovação na contribuição ao crescimento econômico nacional. Também não indicam sustentabilidade deste crescimento. $\mathrm{O}$ ideal seria o Brasil, pela colaboração de seus segmentos de AMDI e de seus governos em todos os níveis, habilitar-se a incorporar em seu sistema produtivo o conhecimento originado da produção científica nacional, a transformar este conhecimento em inovação e desenvolvimento tecnológico, bem como os serviços destes derivados, um dos mercados mais lucrativos do mundo contemporâneo.

Os resultados originados do esforço apoiado pelas políticas nacionais de inovação, ciência e tecnologia, apoiando os três agentes motores de desenvolvimento e inovação, AMDI, gera condições para que o conhecimento desenvolvido nas universidades e demais ICTs alcance a sua aplicação na sociedade, tanto no tecido social quanto no setor produtivo, e nos seus entrelaçamentos, tornando possível o desenvolvimento social, o crescimento econômico sustentável, o avanço tecnológico.

\section{Referências}

ALBUQUERQUE, E. M. et al. Global Interactions Between Firms And Universities: Global Innovation Networks as first steps towards a Global Innovation System. UFMG; CEDEPLAR, 2011. n. 419, 28 p.

BAUMGARTEN, M. Ciência, tecnologia e desenvolvimento: estratégias sustentáveis. Sociologias, v. 6, p. 14-16, 2001.

BEVILACQUA, L.; GALEÃO, A. C. N. R.; PIETROBON-COSTA, F. A influência da retenção de conhecimento na difusão do conhecimento em uma cadeia produtiva. Interpretação de termos de ordem superior. In: WORKSHOP EM DIFUSÃO DO CONHECIMENTO, 2007, Petrópolis. Anais... Petrópolis: Laboratório Nacional de Computação Científica, 2007.

BEVILACQUA, L.; GALEÃO, A. C. N. R.; PIETROBONCOSTA, F. On the Significance of Higher Order Differential Terms in Diffusion Processes. Journal of the Brazilian Society of Mechanical Sciences and Engineering, v. 24, n. 2, p. 166-175, 2011. http://dx.doi. org/10.1590/S1678-58782011000200007

BRASIL. Ministério da Ciência e Tecnologia - MCT. Plano de Ação 2007 - 2010. Brasília: MCT, 2007.

CALIA, R. C.; GUERRINI, F. M.; MOURA, G. L. Innovation networks: From technological development to business model reconfiguration. Technovation, v. 27, p. 426-432, 2007. http://dx.doi.org/10.1016/j. technovation.2006.08.003

CALLIGARIS, A. B.; TORKOMIAN, A. L. V. Benefício do Desenvolvimento de Projetos de Inovação Tecnológica. Revista Produção, v. 13, n. 2, 2003.

CANONGIA, C. et al. Foresight, Inteligência Competitiva e Gestão do Conhecimento: Instrumentos para a 
Gestão da Inovação. Gestão \& Produção, v. 11, n. 2, p. 231-238, 2004. http://dx.doi.org/10.1590/ S0104-530X2004000200009

CAVALERI, S. Toward a More Pragmatic Knowledge Management: Toyota's Experiences in Advancing Innovation. In: NOBRE, F. S.; WALKER, D. Technological, Managerial and Organizational Core Competencies: Dynamic Innovation and Sustainable Development. IGI Global, 2011.

CARDOSO, C. Caracterização do Sistema Regional de Ciência e Tecnologia: Perspectivas Aparentes a partir do Programa de Inovação Tecnológica para Áreas Estratégicas do Estado da Bahia - uma análise do complexo Cultura e Turismo. Revista Eletrônica do Mestrado em Análise Regional, v. 1, 2004.

DAGNINO, R.; GOMES, E. A Relação Universidade Empresa: Comentários sobre um Caso Atípico. Gestão \& Produção, v. 10, n. 3, p. 283-292, 2003.

DE LA MOTTE, J. Science, technology and governance. Continuum, 2001. 246 p.

DEBACKERE, K.; VEUGELERS, R. The role of academic technology transfer organizations in improving industry science links. Research Policy, v. 34, p. 321-342, 2005. http://dx.doi.org/10.1016/j.respol.2004.12.003

FERREIRA, M.; ROCHA, A. T.; ELISA, M. P. Análise dos indicadores de inovação tecnológica no Brasil: comparação entre um grupo de empresas privatizadas e o grupo geral de empresas. Ciência da Informação, v. 30, p. 64-69, 2001.

GUEDES, M.; FORMICA, P. A economia dos parques tecnológicos. ANPROTEC, 1997. 359 p.

GREEN, K.; VERGRAGT, P. Towards sustainable households: a methodology for developing sustainable technological and social innovations. Futures, v. 34, p. 381-400, 2002. http://dx.doi.org/10.1016/ S0016-3287(01)00066-0

HAN, J. et al. Innovation for sustainability: toward a sustainable urban future in industrialized cities. Sustainability Science, v. 7, n. 1, p. 81-100, 2012. http://dx.doi.org/10.1007/s11625-011-0152-2

HOLLANDA, A. B. Novo Dicionário Aurélio da Língua Portuguesa. 3. ed. Nova Fronteira: Positivo, 2007.

HOUAISS, A. Enciclopédia e Dicionário Ilustrado Koogan. Delta, 1993.

INSTITUTO BRASILEIRO DE GEOGRAFIA E ESTATÍSTICA - IBGE. Contas Nacionais. IBGE, 2006.

LEYDESDORFF, L. The Triple Helix of UniversityIndustry-Government Relations. In: CARAYANNIS, E.; CAMPBELL, D. (Eds.). Encyclopedia of Creativity, Innovation, and Entrepreneurship. New York: Springer, 2012.

LIMA, E. C. R.; DOMINGUES, G. B. Crescimento, recessão e probabilidade de reversão do ritmo de crescimento econômico do Brasil. IPEA Boletim estrutural, v. 51, p. 49-52, 2000.

LOIOLA, E.; RIBEIRO, M. T. Política de ciência, tecnologia e inovação como instrumento de governança para o desenvolvimento. Bahia Análise e Dados, v. 14, n. 4, p. 687-706, 2005.

METCALFE, J. S.; FONSECA, M. G. D.; RAMLOGAN, R. Innovation, competition and growth: evolving complexity or complex evolution. Revista Brasileira de Inovação, v. 1, n. 1, p. 85-122, 2002.

MOTA, T. L. N. G. Interação Universidade-Empresa na Sociedade do Conhecimento: Reflexões e Realidade. Revista Ciência da Informação, v. 28, n. 1, 1999.

MOWERY, D.; SAMPAT, B. Universities in national innovation systems. In: FARGERBERG, J.; MOWERY, D.; NELSON, R. (Eds.). The Oxford Handbook of Innovation. Oxford: University Press, 2005.

MUSCIO, A.; QUAGLIONI, D.; SCAPINATO, M. The effects of universities' proximity to industrial districts on university-industry collaboration. China Economic Review, 2012. In press.

NELSON, R. R. What is "commercial" and what is "public" about technology, and what should be? In: ROSENBERG, N.; LANDAU, R. E.; MOWERY, D. (Eds.). Technology and the wealth of nations. Stanford: Stanford University, 1992.

OLIVEIRA FILHO, R. S. et al. Fomento à Publicação Científica e Proteção do Conhecimento Científico. Acta Cirúrgica Brasileira, v. 20, n. 2, 2005. http://dx.doi. org/10.1590/S0102-86502005000800009

ORGANIZATION DU COOPERATION E DEVELOPMENT EUROPEAN - OCDE; MAIN SCIENCE AND TECHNOLOGY INDICATOR - MSTI. Ciência, Tecnologia e Inovação para o Desenvolvimento Nacional - Plano de Ação 2007-2010. Brasília: Ministério da Ciência e Tecnologia, 2007.

PABJAN, B. The use of models in sociology. Physica A: Statistics and Theorical Physics, v. 336, n. 1-2, p. 146-152, 2004. http://dx.doi.org/10.1016/j. physa.2004.01.019

PIETROBON-COSTA, F. Paradigmas para a modelagem da Força Terrestre Brasileira para enfrentar os desafios geopolíticos do Século XXI. Carta Internacional, v. 5, n. 1, p. 107-119, 2010.

PIETROBON-COSTA, F. et al. Simulação da propagação de conhecimento: analogia com um modelo fluidodinâmico, In: WORKSHOP EM DIFUSÃO DO CONHECIMENTO, 2007, Petrópolis. Anais... Petrópolis: Laboratório Nacional de Computação Científica, 2007.

PIETROBON-COSTA, F. et al. innovation and knowledge generation: motor agents of development for sustainability. In: INTERNATIONAL CONFERENCE ON THINKING - ICOT, 14., 2009, Kuala Lumpur. Proceedings... Kuala Lumpur, 2009.

RASCHIATORE, R. A.; MOREIRA, D. A. Inovações na Implementação do Programa Estadual de Microbacias Hidrográficas do Estado de São Paulo. Gestão \& Produção, v. 13, n. 3, p. 517-529, 2006. http://dx.doi. org/10.1590/S0104-530X2006000300013

SIMÕ̃ES, R. et al. A Geografia da Inovação: uma Metodologia de Regionalização das Informações de Gastos em P\&D no Brasil. Revista Brasileira de Inovação, v. 4, p. 157-185, 2005.

SLACK, N.; CHAMBERS, S.; JOHNSTON, R. Administração da produção. 2. ed. São Paulo: Atlas, 2008.

SUGAHARA, C. R.; JANNUZZI, P. M. Estudo do uso de fontes de informação para inovação tecnológica na indústria brasileira. Ciência da Informação, v. 34, n. 1, p. 45-56, 2005. 
TIRONI, L. F. Política de inovação tecnológica escolhas e propostas baseadas na Pintec. São Paulo em Perspectiva, v. 19, p. 46-53, 2005. http://dx.doi.org/10.1590/ S0102-88392005000100004

TOMALA, F.; SÉNÉCHAL, O. Innovation management: a synthesis of academic and industrial points of view. International Journal of Project Management, v. 22, p. 281-287, 2004. http://dx.doi.org/10.1016/j. ijproman.2003.06.003
WU, J. Technological collaboration in product innovation: The role of market competition and sectoral technological intensity. Research Policy, v. 41, n. 2, p. 489-496, 2012. http://dx.doi.org/10.1016/j.respol.2011.09.001

ZAHRA, S. A.; GEORGE, G. The net-enabled business innovation cycle and the evolution of dynamic capabilities. Information Systems Research, v. 13, n. 2 , p. $147-150,2012$. http://dx.doi.org/10.1287/ isre.13.2.147.90

Apêndice 1. Nomenclaturas.

\begin{tabular}{ll}
\hline Siglas & \\
\hline AMDI & Agentes Motores de Desenvolvimento e de Inovação \\
API & Agentes de Apropriação de Inovações \\
EPE & Ensino, Pesquisa e Extensão \\
ETT & Escritório de Transferência de Tecnologia \\
ICT & Instituição de Ciência e Tecnologia \\
IBGE & Instituto Brasileiro de Geografia e Estatística \\
INPI & Instituto Nacional de Propriedade Industrial \\
IPEA & Instituto de Pesquisa Econômica Aplicada \\
MCT & Ministério da Ciência e da Tecnologia \\
MDIC & Ministério de Desenvolvimento, Indústria e Comércio Exterior \\
NIT & Núcleo de Inovação Tecnológica \\
PC & Produtores de Conhecimento (PC) \\
PCDTI & Pesquisa Científica, Desenvolvimento Tecnológico e Inovação \\
PE & Produtores Econômicos Principais \\
PI & Propriedade Intelectual \\
PIB & Produto Interno Bruto \\
SEI & Superintendência de Estudos Econômicos e Sociais da Bahia \\
SNPI & Sistema Nacional de Propriedade Intelectual \\
WIPO & World Intellectual Property Organizatiaons \\
ONU & Organização das Nações Unidas \\
&
\end{tabular}

